IJBPAS, November, Special Issue, 2021, 10(11): 305-312

ISSN: $2277-4998$

International Journal of Biology, Pharmacy and Allied Sciences (IJBPAS)

'A Bridge Betueen Caboratory and QRendo'

Www.ibpas.com

\title{
ELECTRICAL PROPERTIES AND HYDROGEN ADSORPTION OF MULTIWALLED CARBON NANOTUBES OBTAINED FROM AZADIRACHTA INDICA OIL
}

\section{ACHUT SADASHIV MUNDE ${ }^{1 *}$, VINOD ANNASAHEB LOHAKANE ${ }^{1}$, RATNAKAR JAGDISH HOLE ${ }^{1}$, SANDESH VINAYAKRAO JAYBHAYE ${ }^{2}$}

Department of Chemistry, Milind College of Science, Auragabad, MS, India-431001

Department of Chemistry, B. K. Birla College of Science (Autonomous), Kalyan (West) MS, India421304

*Corresponding Author: Achut Sadashiv Munde; E Mail: as mude@yahoo.com

Received $19^{\text {th }}$ July 2021; Revised 20 ${ }^{\text {th }}$ Aug. 2021; Accepted 29 $9^{\text {th }}$ Sept. 2021; Available online $1^{\text {st }}$ Nov. 2021

\section{https://doi.org/10.31032/IJBPAS/2021/10.11.1027}

\begin{abstract}
Neem oil (Azadirachta indica) is a vegetable low cost nonedible oil obtained from its fruits and seeds. Due to easily available in nature with plenty of abundance, and being a rich source of carbon, it can be used as organic precursor for the synthesis of Multiwalled carbon nanotubes (MWCNTs). In this study, we experimented the synthesis MWCNTs by using spray pyrolysis of neem oil over cobalt catalyst under the influence of argon atmosphere at $850^{\circ} \mathrm{C}$. As synthesized MWCNTs were purified using acid treatment and characterized for structural confirmation. The electronic properties of as synthesized and purified MWCNTs was studied using four probe method. We studied the influence of acid treatment to MWCNTs on Surface area, Electrical properties and Hydrogen gas adsorption.
\end{abstract}

Keywords: Adsorption, spray pyrolysis, BET, Semiconductor 


\section{INTRODUCTION}

Azadirachta indica, a key member of botanical family is widely known as Neem oil in urban language [1]. Neem is considered to be a part of India's genetic diversity [2]. It is a vegetable oil obtained from its fruits and seeds. It is easily available in nature with plenty of abundance and also known as margosa oil. Neem tree is indigenous to the Indian subcontinent and has been introduced to many others areas in the tropics [3]. Multiwalled carbon nanotubes has built a concrete platform for a variety of applications across all the fields on globe. Not a single domain has left over where nanotechnology based products are unaware. The literature has witnessed plenty of methodologies for the synthesis MWCNTs by several ways [4]. Some of the methods are based on the chemical synthesis under different experimental conditions. However, these methods had reported afterwards that having costly affair from economic and environmental view point. Therefore, a new arena of green synthesis had come up with efficient methodologies followed by benchmarking end product with desired quality and quantity [5]. Neem is the key element of nature and pretty rich in anti-oxidant property [6]. It is enriched with carbon storage which on exposure to high temperature under catalytic climate yields MWCNTs. Researchers had reported the synthesis of MWCNTs from different natural precursors [7], functionalization with different functional groups [8]. In this study, we have discussed the spray pyrolysis of neem oil with cobalt catalyst as reaction stimulator. A vertical spray pyrolysis furnace equipped with inert gas and water circulator with elevated temperature chamber having temperature range maximum of $1150^{\circ} \mathrm{C}$.

\section{Experimental}

\section{Preparation of Cobalt catalyst}

The economical and qualitative cobalt Nanoparticles was obtained using in-house green method and used as catalyst for synthesis of MWCNTs. The details of this green method is described elsewhere in [9].

\section{Synthesis of MWCNTs}

The MWCNTs was synthesized from Neem oil using a cobalt catalyst, by vertical tube spray pyrolysis method at $850^{\circ} \mathrm{C}$ in an inert atmosphere of argon gas. Details about synthesis of MWCNTs is discussed elsewhere [10].

\section{Purification of MWCNTs}

The as obtained MWCNTs from boats was purified by soaking in 50\% Hydrochloric acid followed by $50 \%$ Nitric acid solution for $24 \mathrm{~h}$ and later it was sonicated for $2 \mathrm{~h}$. Further MWCNTs were washed with water for several 
times and dried at $200^{\circ} \mathrm{C}$ for $3 \mathrm{hrs}$ in muffle furnace.

\section{Characterization of MWCNTs:}

Purified MWCNTs were characterized by X-ray diffraction (XRD) analysis which was performed using Phillips analytical X-ray diffractometer with $\mathrm{Cu} \mathrm{K} \alpha$ radiation running at $45 \mathrm{KV} / 40 \mathrm{~mA}$ in the $2 \theta$ range $2^{\circ}-100^{\circ}$ with step size of 0.02. Specific surface areas were measured using SmartSorb-92/93 model of Smart Instruments Co. Pvt. Ltd. by low temperature nitrogen adsorption using the Brunauer-Emmett-Teller (BET) single point method. The samples were degassed at $150^{\circ} \mathrm{C}$ for 2 hours prior to analysis. The morphological analysis was performed with a Phillips SEM 505 scanning electron microscope.

Surface area measurement by MBA (Methylene Blue Dye Adsorption) and BET method:

In MBA measurement the dye used was 'Methylene blue, (MB)from qualigens fine Chemicals'. Aqueous Solutions of different concentrations of $\mathrm{MB}$ are prepared ranging from 0.25 to $5.0 \mathrm{ppm}$ and the absorbance of these solutions are measured using a UVvisible spectrophotometer at a fixed wavelength of $662 \mathrm{~nm}$. This wavelength is selected for absorption measurement as MB solution shows highest absorbance at $662 \mathrm{~nm}$. Linearity curve of concentration $\mathrm{v} / \mathrm{s}$ absorbance is plotted; the absorbance was found to be linear with regression factor 0.999 . Weighed exactly 100 $\mathrm{mg}$ of test sample (MWCNTs) in $500 \mathrm{ml}$ round bottom flask and added $100 \mathrm{ml}$ of 5 ppm MB solution, shaken to mix properly then this solution is refluxed at $260{ }^{\circ} \mathrm{C}$ temperature for 1 hr. Allowed to cool the solution in same flask and kept for $24 \mathrm{hrs}$ to absorb the MB on test sample. The absorbance of this solution is measured by UV-vis spectrophotometer at $662 \mathrm{~nm}$ wavelength and found the amount of MB dye adsorbed on the test sample from linearity curve and by using formula the specific surface area was calculated. Similarly, the surface area of same test sample was determined using well known scientific apparatus called BET surface area analyzer from SMART instruments and both the results obtained by BET and MBA method were compared.

\section{Electrical properties of MWCNTs:}

Different weight $\%$ of MWCNTs were mixed with HDPE and prepared its chip using hydraulic press. Inserted the prepared chips of different weight $\%$ of MWCNTs in four probe instrument to measure the respective resistivity The schematic representation of four probe instrument to measure the resistivity is as shown in below Figure 1. 


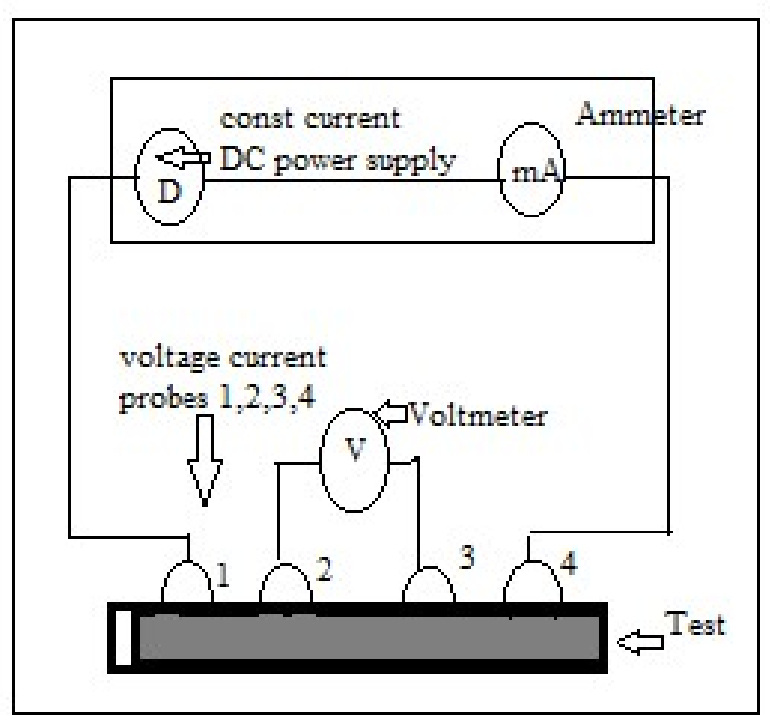

Figure 1: Schematic Diagram of four-point probe method

\section{Hydrogen gas Adsorption Measurement}

Adsorption of hydrogen gas on MWCNTs is carried out using low pressure Sieverts apparatus; this apparatus enables us to measure the hydrogen adsorption of MWCNTs by measuring decrease in hydrogen pressure. A detailed about apparatus, leak test and hydrogen adsorption measurement is discussed elsewhere [10].

\section{RESULTS AND DISCUSSION}

The Diffractogram of as obtained MWCNTs (impure) and Acid treated MWCNTs (purified) shows the reduction of peaks due to metallic impurities present in test sample. Figure 2 (a) represents the major peak at around $26^{\circ}$ is due to carbon i.e. MWCNT and the other two peaks at around $44.4^{\circ}$ and $51.3^{\circ}$ mainly due to metallic impurities i.e. presence of cobalt catalyst in test sample. Intensity of peaks due to metallic impurities gets reduced after purification which represents the purification of MWCNTs with acid treatment.

Scanning Electron Microscope image of purified MWCNTs show the formation of MWCNTs with tube diameter ranging from $28 \mathrm{~nm}$ to $35 \mathrm{~nm}$ size (Figure 3).

The different concentration of MWCNTs with HDPE w/w were exposed to four probe method and the volume resistivity obtained is plotted against concentration as shown in Table 1.

The plot of percentage loading of MWCNTs with HDPE and its volume resistivity is shown below in Figure 4. The Resistivity decreases with the increase in MWCNTs loading with HDPE. Confirms that the MWCNTs are electrically conductive.

The optimal hydrogen storage capacity of purified MWCNTs at different pressure was 
measured by using Sieverts apparatus. It found that the hydrogen adsorption capacity of MWCNTs is 1.20 wt. $\%$ at $11 \mathrm{~kg} / \mathrm{cm}^{3}$ and $3.25 \mathrm{wt} \%$ at $100 \mathrm{~kg} / \mathrm{cm}^{3}$

Resistivity of MWCNTs shows the highest conductance capacity of MWCNTs when spiked with HDPE in higher concentration. i.e. obtained MWCNTs are conducting. The Surface area by MBA method and BET method as obtained is tabulated below along with Hydrogen Gas storage capacity of MWCNTs obtained from Neem oil shown in Table 2.

The surface area of MWCNTs measured by in-house MBA method is found to be comparable to that of BET method and also shows relative Hydrogen gas storage.

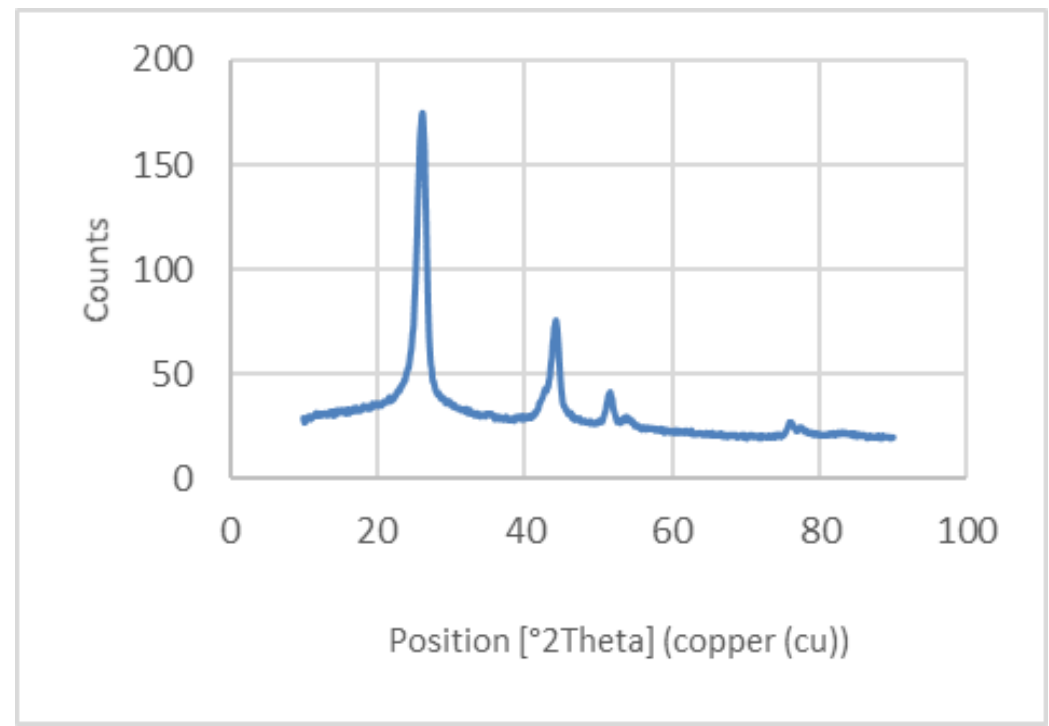

Figure 2(a): X-Ray Diffractogram of As obtained MWCNTs (Impure)

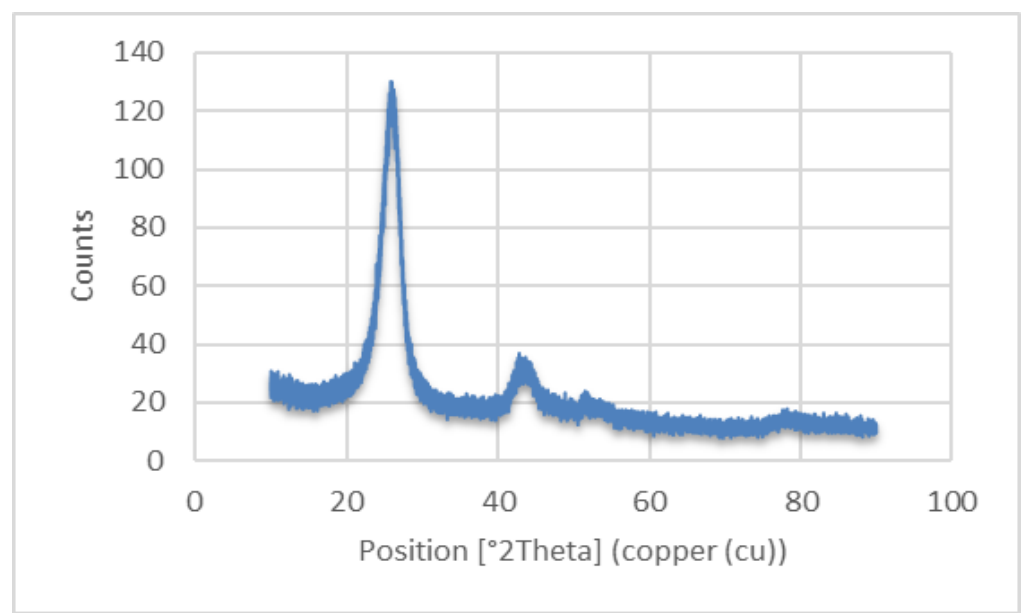

Figure 2(b): X-Ray Diffractogram of purified MWCNTs 


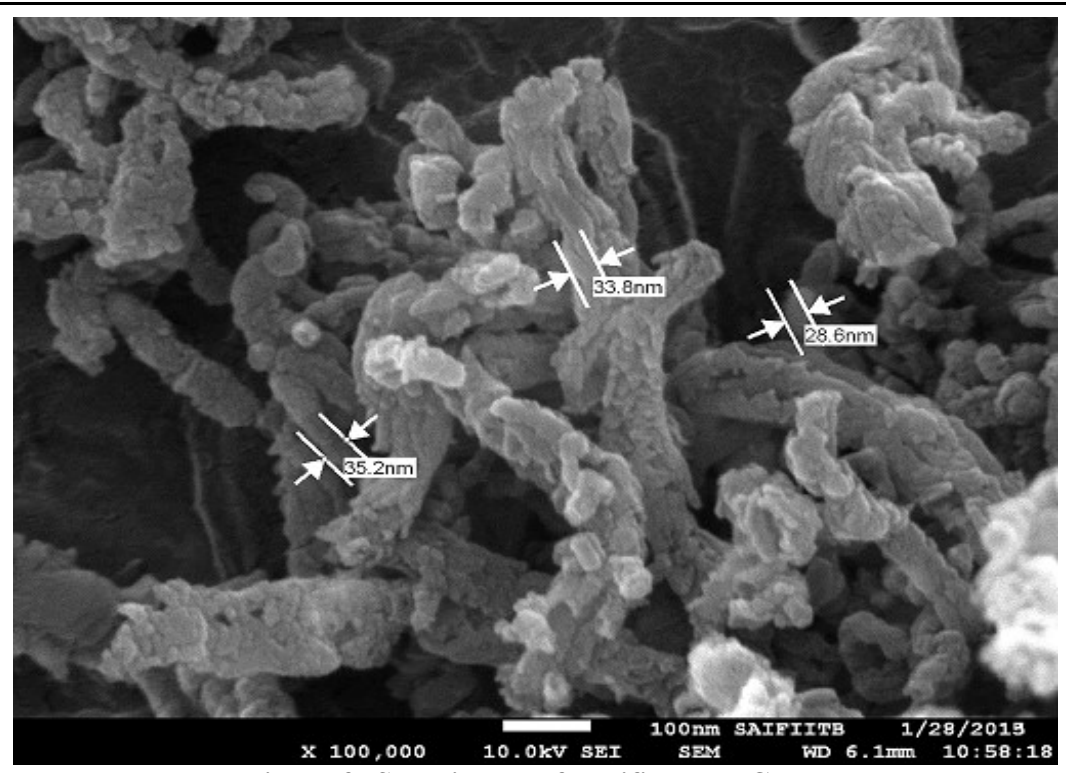

Figure 3: SEM image of purified MWCNTs

Table 1: Percentage Loading of MWCNTs with HDPE and volume resistivity

\begin{tabular}{|c|c|c|}
\hline Sr No & $\begin{array}{c}\text { \% Loading of MWCNTs } \\
\text { with HDPE }\end{array}$ & $\begin{array}{c}\text { Volume Resistivity } \\
\text { (Ohm-cm) }\end{array}$ \\
\hline 1 & 2 & 17 \\
\hline 2 & 4 & 11 \\
\hline 3 & 6 & 8 \\
\hline 4 & 8 & 5 \\
\hline 5 & 10 & 4 \\
\hline 6 & 12 & 3 \\
\hline 7 & 14 & 3.2 \\
\hline 8 & 16 & 3.1 \\
\hline 9 & 18 & 3.2 \\
\hline
\end{tabular}

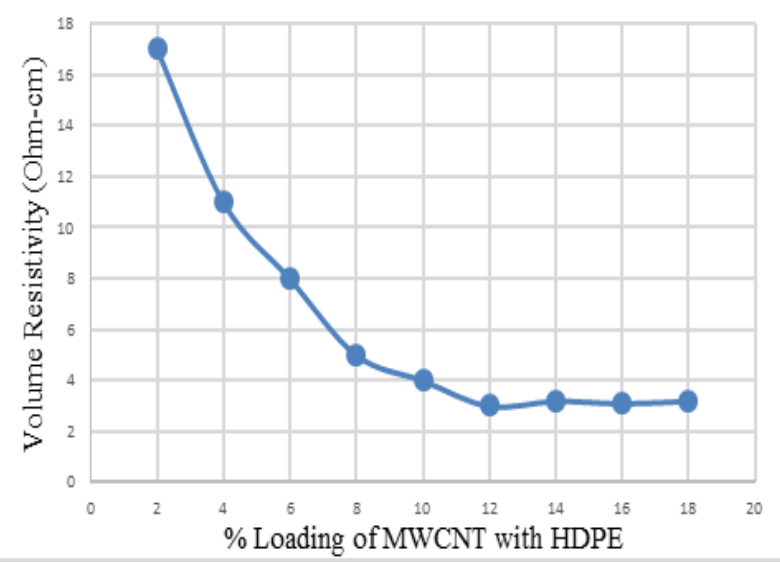

Figure 4: Plot of \% loading of MWCNTs with HDPE v/s volume Resistivity

Table 2: The surface area and Hydrogen storage capacity of MWCNTs

\begin{tabular}{|c|c|c|c|c|}
\hline \multirow[b]{2}{*}{ Sample Details } & \multicolumn{2}{|c|}{ Surface Area $\left(\mathrm{m}^{2} / \mathrm{g}\right)$} & \multicolumn{2}{|c|}{ Hydrogen Gas Storage } \\
\hline & BY MB Adsorption & By BET & At $11 \mathrm{kgcm}^{3}$ & At $100 \mathrm{~kg} / \mathrm{cm}^{3}$ \\
\hline $\begin{array}{l}\text { MWCNTs (Obtained } \\
\text { from Neem Oil) }\end{array}$ & 112 & 118 & 1.20 & 5.25 \\
\hline
\end{tabular}




\section{CONCLUSION}

Naturally occurring precursor i.e. Neem oil is used for the synthesis of MWCNTs. The obtained MWCNTs were purified and characterized using different analytical tools and also studied its applications in Hydrogen gas adsorption and electrical property i.e. resistivity. Along with surface area measurement of MWCNTs with in-house Methylene Blue Adsorption and existing BET method which are found to be comparable and in-house MBA method can be replaced to that of existing BET method of surface area measurement. The results of resistivity measurement shows that the MWCNTs are electrically conducting.

\section{Acknowledgement}

The authors owe their sincere thanks to Department of Chemistry, Milind College of Science, Aurangabad, M.S. and Nano Technology Research Laboratory of B. K. Birla College (Autonomous) Kalyan, M.S for their research guidance and motivational inputs to shape up the presented research.

\section{REFERENCES}

$\begin{array}{lr}\text { [1] "Azadirachtarica". Germplasm } \\ \text { Resources } & \text { Information } \\ \text { network (GRIN). Agricultural } & \text { Research } \\ \text { Service (ARS), United } & \text { States }\end{array}$

Department of Agriculture (USDA).

Retrieved 9 June 2017.

[2] Rius, G. Technologies of Carbon Materials. Syntheses and Preparations. In Carbon for Sensing Devices; Springer: Cham, Switzerland, pp. 1542,2015

[3] Vinod. L, Ratnakar. H, Sandesh. J and Achut.M "Plant based reducing agent for Nickel nanoparticles" journal of biological chemical chronicles 5(3) pp 198-201,2019

[4] Ghimeray A. K., Jin C. W., Ghimire B. K., Cho D. H. Antioxidant activity and Quantitative estimation of azadirachtin and nimbin in Azadirachta indica A. Juss grown in foothills of Nepal. African Journal of Biotechnology. 8(13): 3084-3091 2009.

[5] Vinod. L, Ratnakar. H, Sandesh. J and Achut.M Surface area measurement of carbon nanomaterials obtained from Castor oil". International journal of scientific research in science, Engineering and technology, vol 5 pp 193-196, 2018.

[6] Sandesh Jaybhaye, Pandurang Satpute and Mandar Medhi, "Carboxylation of Multi-walled Carbon Nanotubes by Ultra sonication", Int. Journal of 
Chemistry, Vol. 3 (2) pp 224 228,2014 .

[7] CVD synthesis of carbon nanotubes using a finely dispersed cobalt catalyst and their use I In double layer electrochemical capacitors, Electrochimica Acta vol 48(23) PP 3439-3446, 200.

[8] Maheshwar Sharon,T. Soga,Rakesh Afre, D.Sathiyamoorthy, K.Dasgupta, Sunil bhradwaj, Madhuri Sharon, Sandesh Jaybhaye "Hdrogen storage by carbon materials synthesized from oil seeds and fibrous plant materials" Interrnational journal of Hydrogen energy vol.32(17) PP4238-4249, 2007. 